\title{
EXPLORING THE COVID-19 PANDEMIC AS A CATALYST FOR STIMULATING FUTURE RESEARCH AGENDAS FOR MANAGING CRISES AND DISASTERS AT INTERNATIONAL SPORT EVENTS
}

\author{
LEE MILES* AND RICHARD SHIPWAY† \\ *Bournemouth University Disaster Management Centre (BUDMC), Bournemouth University, \\ Poole, UK \\ $\dagger$ Department of Sport \& Event Management, Faculty of Management, Bournemouth University, \\ Poole, UK
}

\begin{abstract}
While the interdisciplinary study of crisis, disaster, and emergency management has become increasingly sophisticated, the identification of synergies, useful concepts, and future research agendas in relation to studies within the domain of sport event management to inform these areas, is still at a very early stage of development. The far-reaching global impact of the COVID-19 pandemic further illustrates the timely importance of this research agenda for both sports events and broader studies in festivals and events. The purpose of this article is to critically scope the resilience landscape to help further understand how studies on both international sports events (ISEs) specifically, and both sport and event management studies more generally, could be better informed by disaster management and resilience studies. The article highlights eight key thematic areas that merits further investigation and combines to identify a multidisciplinary research agenda and framework for advancing knowledge on managing crises and disasters in both sport and event management studies.
\end{abstract}

Key words: Resilience; Sports events; Crisis; Disaster management; COVID-19 coronavirus

\section{Introduction}

The aim of this article is to make a value-added contribution to current thinking on sport event management studies and resilience, with specific focus on international sports events (ISEs). The global societal impact of the COVID-19 pandemic highlights the timely importance of this proposed research agenda not only for sports events but broader studies in festival and events. Previous classifications and definitions of international sports events (Getz, 2008; Hiller, 2000; Horne, 2007; Müller, 2015; Shipway \& Miles, 2020) have not explicitly incorporated critical dialogue on the impact

Address correspondence to Dr. Richard Shipway, Department of Sport \& Event Management, Faculty of Management, Bournemouth University, D237, Dorset House, Talbot Campus, Fern Barrow, Poole, BH12 5BB, UK. Tel: +44 (0) 1202965692 ; E-mail: rshipway@bournemouth.ac.uk 
of crises and disasters. This is surprising given that such large sports events are using criteria that are, in some ways, similar to those used to define critical infrastructure (CIs) in the more established crisis and disaster management literature (Boin \& McConnell, 2007). This also implies notable risk factors that may become prominent at times of external shocks, and even result in discernible loss of life, sizable casualties, and substantial infrastructural damage. Whatever the scenario, the impact of an external shock, such as a terrorist attack or the COVID-19 pandemic, will have notable impacts on sport markets and even tourism flows (Sönmez, Apostolopoulos, \& Tarlow, 1999), and thus international sports events represent one of the most significant CIs of both the sports and events industries.

Although some may argue that international sports events can be incorporated into notions of "organizational resilience" (Bhamra, 2016; Burnard \& Bhamra, 2011), the premise of this article is to suggest there is a need to consider the concept of "Sport Event and Venue Resilience" given their criticality as CIs for sport event-based activity. This article follows the assertion of Shipway and Miles (2020) that future studies on ISEs and festivals more generally could be informed by existing work in disaster management and resilience studies. As such, this article will now further scope the resilience landscape in terms of future research agendas that may help us to further understand how both sport and event management studies more broadly, via specific reference to ISEs, could be informed by disaster management and resilience studies.

This seems particularly significant given global initiatives, such as the United Nations Sendai Framework for Disaster Risk Reduction 20152030, are creating a central profile for resilience as part of a comprehensive, inclusion and "all of society" approach to crisis and disaster management (United Nations, 2014, p. 23). The Sendai Framework urges "non-State stakeholders," such as business, professional associations, and the private sector, to be more fully integrated into international disaster management to enhance resilience (United Nations, 2014, p. 23), and this includes reference to the tourism industry (United Nations, 2014). Similarly, it has become increasingly recognized that societal actors and stakeholders are critical to enhancing "multifaceted resilience" (Alexander,
2013; European Commission, 2015). This logic extends to ISEs that are highly complex, involve strong levels of international interdependency, and attract global interest and participation. Interdependency also increases vulnerability to international crises and disasters that are ever more prevalent due to the impacts of climatic change, globalization, and international political trends (Miles, 2016a). The escalating impact of the COVID-19 pandemic illustrated these vulnerabilities on a global scale, which effectively decimated the global calendar of sports events from March 2020 onwards.

According to Chandler and Coaffee (2017) resilience is often defined "as a capacity to prepare for, to respond to, or to bounce back from problems or perturbations and disturbances" (p. 4) that can also affect affected sports communities, organizations, and even events (see Hall, 2016). From March 2020 onwards, this was the situation encountered by the global sports events industry and it was equally catastrophic for the wider domain of festivals, urban recreation gatherings, tourism, and entertainment venues. Moreover, it is argued that resilience enhances organizational performance (Adger, 2006), and this has particular connotations for the organization of ISEs, including mega-sports events (Shipway, 2018; Shipway \& Miles, 2019).

Ultimately, enhanced resilience should shape responsiveness and even act as a major catalyst for change (Miles, 2016b). Hence, there seems to be a demonstrable link between the interests and agendas of studies in both sport and event management and crisis and disaster management, and in particularly in the context of ISEs. Nevertheless, even though sport represent a significant (nonstate) sector, it is noteworthy that international frameworks such as the Sendai Framework do not make specific reference to the sports industry (United Nations, 2014, p. 20). This would perhaps indicate that considerable future work is required to investigate the nature, complexity, and connectivity of the practical links between sport event management and disaster management as part of both the academic and industry practice dimensions of the "resilience turn" (Coaffee \& Fussey, 2017). This is particularly pertinent if both the sports and events industries are to meet aspirations that resilience is "an approach that has the potential to bridge different fields" (de Milliano \& Jurriens, 2017, p. 260). 
The purpose of this article is to critique ISEs through the lens of resilience, and that this is more feasible through adopting a more "bottom-up" ethos within the domain of sport event management, with the focus on (1) sports organizations/events, (2) societal/community sport event aspects, and (3) the individual sport event participant or spectator. It also postulates that the concept of resilience "rests on the notion of capacity-the capacity to recover from crisis and conflict" (Haldrup \& Rosen, 2013, p. 131). Thus, the emphasis will be (1) a capacity focus, (2) a movement away from top-down to bottom-up approaches, and (3) advocating future studies that adopt a process orientation, whereby ISEs can move from building to developing and enhancing resilience.

The global responses to the COVID-19 pandemic illustrated the increasingly important role of community based, bottom-up approaches to dealing with global crises and fostering greater resilience. From this perspective, the desire to achieve greater societal resilience towards the onset of COVID-19 had implications for ISEs, which were increasingly seen in the context of representing dangerous "mass gatherings" of people that would be a forum for wider community transmission of the disease. This rapidly resulted in the widespread cancellation or postponement of ISEs and sports programs being dramatically impacted upon by the "societal" resilience implications of the pandemic.

\section{Paucity of Studies on Managing Crises and Disasters for Sport Events}

An initial review of literature on crisis and emergency management in sport (Shipway \& Miles, 2020) indicated a relative paucity of studies. In the sport event management space, even where previous studies exist, they are often restricted to very limited development of conceptual frameworks that make almost passing analysis in relation to ISEs (see Shipway, 2018; Shipway \& Miles, 2019). Additionally, in the wider field of both sport and event management studies, crisis and emergency dimensions are not mentioned with any significant depth or with reference to the existing crisis and disaster management literature (see Hall, 2016). Studies of resilience in sport to date are primarily associated with either community sports clubs' responses to natural disasters (Filo, Cuskelly, \& Wicker, 2015), the relationship between team identification and social well-being in times of adversity (Inoue, Funk, Wann, Yoshida, \& Nakazawa, 2015), disaster relief activities implemented by sports organizations and athletes (Inoue \& Havard, 2015), or the psychological resilience of the individual athlete or team, from a performance perspective (Galli $\&$ Gonzalez, 2015). These latter studies are interested in resilience from the perspective of humans (athletes and fans) who have been exposed to challenging circumstances and their ability to respond positively and overcome personal adversity.

Despite these contributions, within studies on sport management specifically the field is at an early and descriptive stage with considerable work to be undertaken on shaping research agendas and/ or future directions. This assumption is equally applicable to studies embedded within the event and festival literature. As such, in the context of both ISEs and broader sport and event management dimensions, it is essential to draw on the broader experiences of disaster and crisis management studies to identify gaps in knowledge, and contribute to understanding future research directions.

It could be argued that ISEs could be theoretically covered under the wider rubric of tourism crisis and disaster management works. There should be implicit features covered by conceptual works that focus on risk management frameworks (Evans \& Elphick, 2005; Faulkner, 2001; Ritchie, 2004), disaster risk assessment modelings and forecasting for tourism (Tsai \& Chen, 2011), and travel-related risks (Ritchie, Chien, \& Sharifpour, 2017) to name just a few. There is also an ever-growing literature within tourism studies in relation to various forms of resilience (e.g., Filimonau \& Coteau, 2020; Mair, Ritchie, \& Walters, 2016), although it appears that so far there has been little consensus created around either unifying concepts within the tourism space (Aliperti et al., 2019), or any specific attempts to extend these to specifically ISEs. However, in most instances, and despite their size and visibility, ISEs remain a largely neglected aspect where the practicalities of integrating them into either sport or event management-related frameworks has not been fully recognized or fully linked to resilience (Shipway \& Miles, 2020).

Nevertheless, there remains an important research waypoint as regards the existing research on disaster 
management, sport, and risk management within both the sport and event studies contexts. This waypoint can act as a key observation for studies of resilience aspects of ISEs. It would appear that the majority of tourism crisis management approaches tend to be dominated either by a more "top down" tradition (Jiang, Ritchie, \& Beckendorff, 2017), with the focus on organizations, planning and cooperation, and addressing issues relating to mitigation, preparation, response, and recovery, or a strong focus on "horizontal" stakeholder cooperation, with more attention to business and destination operations (Jiang \& Ritchie, 2017; Pyke, Law, Jiang, \& De Lacy, 2018). In existing tourism crisis and disaster management studies, this has been compounded by a strong propensity to focus on cases and case studies (Jiang et al., 2017; Pyke, De Lacy, Law, \& Jiang, 2016). The majority of these case studies have centered on particular disaster episodes, rather than systematically focusing on thematic points like ISEs.

A Thematic Framework for Scoping

Resilience at International Sports Events

When scoping resilience landscapes, much of the seminal literature within crisis and disaster management studies highlight that "context is everything" (Haldrup \& Rosen, 2013, p. 137). As such, this theoretical exploration is embedded within a resilience perspective on ISEs, as an influential component of sport event management studies.

Therefore, this article undertakes two tasks. First, it evaluates how relevant crises and disaster management approaches can provide value added to understanding major sporting events, and where there are appropriate synergies for future development. Second, and based on the existing approaches and literature within crisis and disaster management studies, the article outlines research agendas where the focus and interest of sport event management and crisis and disaster management intersect using the thematic area of ISEs as illustration, as an integral part of the sport event management dimension (Shipway, 2018). On this basis, it will be argued that further work on aspects of what the authors label as sport event and venue resilience can provide further added value in understanding why and how ISEs practice resilience in the future, and can become more robust at handling crises and disasters (Shipway \& Miles, 2020). The COVID-19 pandemic is a pertinent example of the vital need for better understanding resilience within the context of ISEs.

As such, a particular scoping approach has been adopted. First, there was the completion of a thorough scope of the (very limited) number of main articles, publications, and works dealing with ISEs emanating from the realms of sports, events, and crisis and disaster management fields in order to position the study. Second, there was an evaluation and analytical grouping of the main outstanding research agendas which were identified and/or missing, from the rather limited number of studies that exist. Third, this scoping review then duly informed the construction of a thematic framework that could structure future attention and discussion of a series of research agendas on ISEs, that encourages interaction between the interdisciplinary areas of sports, events, and disaster management studies, as previously advocated by Shipway (2018).

\section{Future Resilience Research Agendas for International Sports Events}

Based on the scoping review of past and present studies within the domain of crisis and disaster management, a proposed thematic framework (Fig. 1) is introduced highlighting a series of eight resilience research agendas that merit further investigation in the context of future studies in sport event management. These themes will now be explored.

\section{Criticality of Venue Resilience of International Sports Events}

The successful delivery of sport-related events is often reliant upon having the appropriate capacity of suitable and effective international sports venues (ISVs). For the purpose of this article, an ISV will be defined as a "structure, building, or place in which a sporting competition is held" (Shipway \& Fyall, 2012, p. 6). They represent physical structures, buildings, or places that host large groups of participants or spectators and include arenas, stadiums, convention centers, racetracks, and amphitheaters (Masteralexis, Barr, \& Hums, 2012). Within any broad ISV definition used for the context of 


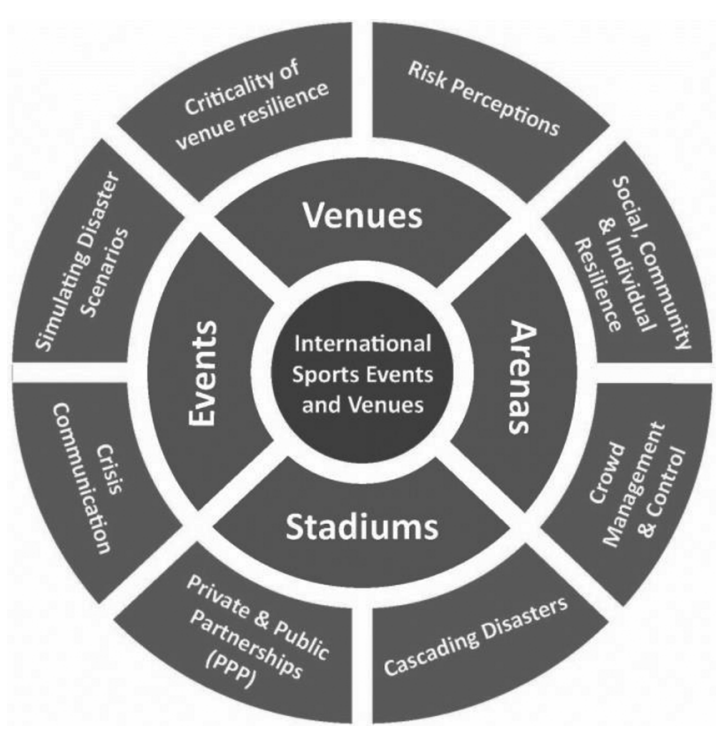

Figure 1. A framework for understanding crisis and disaster management at international sports events and venues.

exploring resilience, it is important to recognize notable variations with differences between ISAs (indoor facilities that host sports and entertainment events) and international sports stadium (ISS; outdoor or domed facilities) (Shipway \& Miles, 2019).

Yet, from a crisis and disaster management perspective, ISVs have important spatial and temporal considerations that influence sport management studies more generally. First, ISVs can be understood through the disaster management lenses of critical infrastructure (CI), and as such, they represent in practice a key influence upon developing, maintaining, and enhancing the resilience of sportbased events. In a societal context, CI is a term used by governments to describe assets that are essential to the functioning of a society or economy, including areas such as agriculture, heating sources, water supply, public health, transportation, electricity generation, financial services, and telecommunications (Shipway \& Miles, 2019). Importantly, CI is regarded as being those critical systems and assets that are vital to the running of a particular function of a society, economy, and nation. They are so highly interconnected that any respective failure in a CI will have very serious impacts upon the viable operation or delivery of a function (United Nations Office of Disaster Risk Reduction [UNDRR], 2017).
Drawing upon notions of sociotechnical and even technocratic concepts of resilience, ISEs and tournaments require key $\mathrm{CI}$ and physical locations to enable them to fulfill their schedule(s), often within particularly tight time scales. For instance, during the Olympic Games, the "flagship" Olympic Stadium is often newly built, dedicated to the codelivery of differing forms of athletics, as well as being the physical and symbolic representation of that respective Games at a particular point in time. Such new venues, and thereby technologically advanced locations in terms of safety features, may also contribute towards the profile of the event as a visitor attraction (Shipway, 2018). Similarly, some Olympic sports, such as cycling, require dedicated often high-tech venues, such as the velodrome. These venues will not only meet Olympic technical standards but are also designed to deliver seamless sport to a worldwide audience. More fundamentally, they also extend the global profile and image of the respective sporting destination (Higham, 2005).

First, from the perspective of resilience, they are very close to representing a physical CI whereby any disruption or loss of functioning would have serious implications for the overall viability of the ISE or tournament itself. Secondly, substitution of venue may be practically impossible or where it is possible it has extremely serious systemic, economic, or reputational implications (UNDRR, 2017). Ultimately, this is likely to damage the attractiveness of both the destination and most probably the host nation. From this perspective, ISVs are very much the CIs of sporting events. This assessment is likely before the complex characteristics of the size/scale, reach, and duration that differentiate ISEs are factored into any equation (Horne, 2007; Jago \& Shaw, 1998; Müller, 2015; Shipway \& Miles, 2020). The severity of the impact of a crisis or disaster at a major sporting tournament, and in turn the impact upon the attractiveness of that host city or destination, is partially contingent on the differing degrees of criticality and vulnerability of particular venues, and the resilience of a major sporting event or tournament to proceed with or without them. It is suggested that the more "mega" the ISE, the more the complexity and importance of understanding venues, as a form of CI, becomes (Shipway \& Miles, 2019).

Indeed, the role of ISVs extends beyond sport to far broader leisure event activities given that 
they also host non-sporting events such as indoor/ outdoor concerts where performers, like sports teams, attract large crowds. The terrorist atrocities in May 2017 at the Ariana Grande concert at the MEN Arena in Manchester (UK) further illustrate the vulnerability of these multiuse arenas (Kerslake Arena Review, 2018). Here, the survivability of stadiums and arenas, and thereby their criticality to ISEs, may be contingent on understanding risk and effective multiagency cooperation. These risks extend beyond the sport domain given their multiple usage in a range of broader leisure event settings. Hence, within the context of future sport event management studies, there is a clear need to better understand sport event and venue resilience.

The criticality of venue resilience as a variable affecting sport event-related spaces may be more complicated than it first appears. Venue resilience may be reliant on contingencies across multiple hazards and threats in the nonsporting domain that may ultimately influence its operational capacity to be a reliable international sports venue. For example, in the tourism context, although it is acknowledged that such calculations should be part of any effective tourism crisis and disaster management framework (Ritchie, 2004), and lies within the grounds of effective risk management, there has been a strong tendency within tourism crisis management studies to focus on its intrinsic impact on tourism flows and reputation. A (re)focus on ISEs illustrates the importance of reaching "beyond the rhetoric" (Santana, 2004). In doing so, drawing from emergency planning literature and as an integral feature of future ISE resilience agendas, it is advisable to focus on provision for alternate venues should disaster occur. Convention centers are just one example. It is also important to focus on the multiagency cooperation also necessary to support these alternative venues as part of enhanced venue resilience (Kerslake Arena Review, 2018). This may have significant reputational risks for both mega- and larger-scale major sports events, where there is expectation of the very best facilities given their global reach, scope, and reputations.

By incorporating a resilience perspective from disaster management studies, the enhanced profiling and criticality of both international sports events and venues can be further understood within sport event management studies. It adds insights into the measures required to manage the coexistence between venue and event resilience. Whether or not specific tournaments can proceed will most probably be contingent on key development and delivery of emergency planning that understands and enables an ISE to proceed independently of how particular venues are affected by an incident. Similarly, it is important to consider whether the viability of a tournament would be impacted depending on the type of natural hazard or manmade threat/incident (Kerslake Arena Review, 2018). The COVID-19 pandemic illustrated how the viability of both sport and non-sport-related events and festivals were significantly impacted. The agenda around the sport event and venue resilience components of tournaments and events raises questions about both degrees of criticality of infrastructure and the respective sport organizers' ability to respond, that clearly has substantial sport, leisure, and event implications.

\section{Risk Perception of International Sports Events and Venues}

Scholars from the realms of tourism crisis and disaster management have been at the forefront of understanding risk perceptions and management within tourism studies (see Reisinger \& Mavondo, 2005; Ritchie et al., 2017). Particular strengths lie in extending risk management frameworks (Ritchie, 2004), and in understanding the risk perceptions of travelers (Kozak, Crotts, \& Law, 2007), including Olympic tourists (Walters, Shipway, Miles, \& Aldrigui, 2017).

However, in more sport event-specific contexts there are several areas where crisis and disaster management techniques can provide better advancement of ISE resilience, and thereby more robustly inform elements of sport event and venue resilience. First, there is added value in building in crisis and disaster management techniques into hazard identification, and a stronger profiling of risk reduction agendas as part of international resilience agendas. In terms of additions to the sport event management literature, particular added value could arise from future studies that explore a more detailed understanding of human and social dimensions of hazards that are linked to crises and emergencies (Ammon, Southall, \& Blair, 2004). 
In this respect resilience is also characterized as being about strengthening the relationship between people and their environments that contain hazards. Fundamentally, ISEs attract large congregations of humans, in terms of staffing, stewarding, fans, or more general public crowds (Tarlow, 2017). Therefore, given that they are essentially locations of human activity, then "man-made" threats such as crowd incidents (like riots, demonstrations, crowd crushes, and stampedes) as well as terrorist incidents (such as bombings, shootings, hostage taking, and hijacking) are examples of anthropogenic hazards that have direct bearing on the resilience capacity of ISEs, as the COVID-19 pandemic illustrated.

Equally, in some areas of the world there is likelihood of natural (geophysical) hazards that could potentially impact on ISEs that could emanate from geological, meteorological, oceanographic, hydrological, or biological causes. As such, these areas may feature as potential sport-based hazards requiring further investigation. The cancellation of the 2012 New York City Marathon in the aftermath of "Hurricane Sandy" is one sport event example of a major incident linked to a meteorological hazard. Authors such as Alexander (2016) have suggested that the distinction between natural and humaninduced disasters is not clear cut, and it could be argued that the cause of some natural disasters lie as much in the failings of human organization, such as human vulnerability to disaster, as it does in extreme natural events.

Second, existing disaster management studies can aid in understanding that ISEs also have implications for the level of risk, risk analysis, risk management, and resilience associated with the magnitude/size, levels of internationalization, complexity, and importance/resonance of major sporting events (Hall, Marciani, Cooper, \& Rolen, 2008). Yet, Carey and Mason (2016) identified that the majority of previous research linked to crisis and/or disaster management within the domain of sports studies emanates from a tourism perspective. Particular attention has been focused on the retention of visitors to specific locations or events (Faulkner, 2001; Laws \& Prideaux, 2006; Ritchie, 2004). They suggest that the key area related to crisis management within the sport management literature is risk management and indicate that an extensive body of knowledge has emerged that examines the mitigation and management of risk associated with the hosting of major and megasports events (Leopkey \& Parent, 2009; Tarlow, 2002; Taylor \& Toohey, 2007). However, ISEs are not typical sport attractions, and sporting venues cannot always be treated as standard infrastructure given the specific nature of sports events and their audiences (Shipway \& Miles, 2020).

Third, although studies have been undertaken on risk aspects in terms of tourism crisis and disaster management, risk reduction agendas, particularly those emanating from UNDRR, have not attracted the same level of thematic attention, or been explicitly explored in published sport management works. To date, the primary focus has been on crisis guidance emanating from the World Tourism Organization (WTO). These risk reduction agendas, which in practice are central to crisis and disaster management perspectives on critical infrastructures (Boin \& McConnell, 2007), have not been the subject of discussions in the realms of broader sport or event management studies. The practice of organizing ISEs, increasingly in host locations across the developing world, illustrates that risk reduction agendas are in practice assuming ever greater importance and resonance within the "organizational resilience" practice of sports events. On this basis, a more detailed critique on the role of risk reduction as part of practical "strategic" resilience (Burnard \& Bhamra, 2011) is still required as part of a more explicit focus on ISEs.

\section{Synergizing Wider Social, Community, and Individual Resilience Perspectives}

There is potential for a major research agenda exploring linkages between sport event management and disaster management studies in terms of understanding the nuances and roles of social/ community and individual resilience. This is important in several ways. First, the delivery of ISEs is often perceived and gauged in terms of wider legacies affecting surrounding host regions and countries (Dickson, Benson, \& Blackman, 2011; Preuss, 2007). Second, risk perception of ISEs cannot be easily detached from that of the host locations, which in themselves have varying levels of associated risk. As discussions around both the zika virus outbreaks in the build up to the Rio 2016 
Games and the COVID-19 global pandemic illustrated, the actual risk perception and assessments may be related to the wider level of social and/or community resilience rather than directly related to a threat or hazard to a specific sporting activity, event, or venue (Walters et al., 2017). In the case of Brazil in 2016 and again globally in 2020 with the COVID-19 pandemic, it was not always a manmade terrorist attack or the impact of a hurricane that were perceived as the only threats prioritized by fans, tourists, and the general public. Rather there was also an accompanying fear of spread of disease for athletes and crowds stemming from local outbreaks of diseases in the surrounding areas and communities (Tarlow, 2017). Hence, community resilience is intrinsically related to risk perceptions and assessment at sports events.

Therefore, it is useful to understand not just the resilience aspects of the particular types of ISEs in terms of hosting the event, but to also have a more advanced appreciation of the wider communities in terms of their respective community resilience and its relationship to sport event legacies (Shipway, 2007). For example, within the sport tourism literature the role of communities has been extensively documented in terms of enhancing destination attractiveness (Higham \& Hinch, 2018) with little attention to the resilience aspects of those respective communities. Even in the realms of literature on tourism crisis management, it can be argued that community resilience has received only anecdotal attention as part of case studies or as part broader schemes such as network approaches or strategic management (Jiang et al., 2017; Mair et al., 2016). In contrast, the broader crisis and disaster management studies have placed a great emphasis on understanding community resilience and in locating it within international resilience agendas in order to support and facilitate disaster management (Atkinson, 2012). There has been less of a tendency to focus exclusively on one specific site or in this case, a sporting event or venue. As Heath-Kelly (2017) noted: "danger is everywhere" and that "disaster is no longer defined as the physical event or the enemy which impacts upon us, but the lack of preparation for such inevitability" (p. 311). Equally in terms of sport event legacy discussions there remains a need to consider these implications in relation to sport event and venue resilience (Shipway \& Miles, 2020).
New infrastructure such as sports venues, arenas, and stadiums that are often built for the hosting of specific sporting tournaments and events can often be utilized as major locations for evacuation or casualty treatment long after the sport events have concluded. One such example was the controversies around the usage of the Louisiana Super Dome in New Orleans as a major shelter during and after Hurricane Katrina in 2005. This avoids them being an unused resource or going to ruin. Yet, there is substantial scope when critiquing legacy effects of major sport tournaments to take into account resilience considerations and variations between resilience planning centered on particular sports events and those of the wider host communities. It is these characteristics that present challenges for sports event organizers and stakeholders when planning and preparing to protect against potential crises and disasters. This is not least because resilience could include protecting legacies, associated services, and even linked events (Shipway \& Miles, 2019). On this basis, it is surprising that resilience and crisis and disaster management considerations are not more strongly factored into sports event equations when trying to understand the importance of sport event legacies (Shipway, 2018).

Third, there is a need to explore the particular nature of individuals and individual resilience. For example, more research is required on the role of fans as tourists and their perceptions of risk that shape where they travel and whether their perceptions may be different from those usually equated with tourists or the traveling public (Walters et al., 2017). This is important given the role of fan identity and allegiance to particular teams, sports, and even sport-related tournaments that may shape the level of individual resilience, and their levels of acceptance of risk taking (Jones, 2008; Qi, Gibson, \& Zhang, 2009).

It is important to recognize that generic risks associated with individual sports also have particular sporting histories and contexts that affect behavior. In a European context, there are widely publicized past tragic incidents such as stadia fires (Bradford, UK in 1985), crowd-related disasters (Hillsborough, Sheffield, UK in 1989), or terrorism (Paris, France in 2015) to name just a few, that cover wider issues related to terrorism, hooliganism, crowd disorder, assault, vandalism, logistical failure, fraud, 
theft, and inclement weather (Stevens \& Glendinning, 2007). One nexus is that understanding venue resilience requires emergency planning and risk assessment to account for the specific nature of fandom and sports crowds. In simple terms, sports fans are not just tourists (Walters et al., 2017), or travelers (Kozak et al., 2007), or consumers (Mair et al., 2016), but are also distinctive in their own right as a group with clear sporting identities that affect behavior (Lock \& Heere, 2017). As such, this may affect their risk perception, and susceptibilities to risk taking and/or risk aversion (Kozak et al., 2007). The initial outbreak of the Coronavirus COVID-19 demonstrated that many sports fans were still willing to travel and support their teams (Walters et al., 2017), despite the inherent risk associated with attending sports events, as a form of mass gathering where they were in close proximity to other supporters. Indeed, this behavior has notable implications for the management of sports events in developing countries, like Africa, where disaster management systems are less robust (Gilbert et al., 2020).

Given that fandom incorporates tribal allegiances, there is a clear area of future research inquiry in understanding whether sports fans are more open to risk taking, or less risk averse, in attending sports events and tournaments around the globe, given they strongly prioritize fan allegiance and fan behavior. Hence, there may be specific assumptions relating to the behavior of fans and sports crowds (Stott, Hoggett, \& Pearson, 2012; Stott, West, \& Radburn, 2016) that make them different from the normal assumptions about crowd control used in emergency planning. Based on the current existing body of knowledge, there may be different assumptions and expectations emanating from sport management-related literature that could inform emergency planning at ISEs on individual resilience and individual risk perceptions of fans. Equally, the crisis and disaster management literature with its identification of key disaster management cycles should be factored more clearly into sport event and venue resilience, and in particular whether expectations around fans and individual resilience may vary at differing points in handling crises and disasters. For example, further research should be undertaken on the crisis recovery phase, such as after a terrorist incident like in Paris in
2015 and the COVID-19 pandemic, examining fans' expectations in relation to sport tournaments, high-profile annual sporting events, and destination safety.

\section{Standing out From and With the Crowd}

Another area where existing studies in crisis and disaster management may be useful in the sport event management context is better understanding crowd sourcing, management, and control. Crowd management and control at ISEs remains an increasingly important element of venue safety and security (Stott et al., 2012). Doukas (2006, cited in Hall, Cooper, Marciani, \& McGee, 2012) define crowd management as "every component of the game or event from the design of the stadium or arena to the game itself and the protection of patrons from unforeseeable risk of harm from other individuals or the actual facility itself' (p. 2). Crowds need to be managed for several reasons. First, large gatherings raise the likelihood that something will happen; second, changes in action tend to be slower and more complex; and third, communications are slower and more complicated than normal. Two previously mentioned incidents of crowd management disasters at UK sporting events, the 1985 Bradford stadium fire and the 1989 Hillsborough disaster, not only had strategic and operational management implications for sports venues, but to the current day have resulted in significant psychological and well-being impacts on spectators, event organizers, and families both directly and indirectly affected.

Yet shared learning is a mutual process and existing sport event management studies that understand the collective identities and behavior of fans can also help to further understand the identity functions of crowds, that can enhance risk assessments. This will also contribute to more accurate exercising and simulations (see resilience agenda 8) that constitute a key part of crisis and disaster management studies. Hence, sport event managers and organizations can potentially learn from how disaster management studies stress the importance of "social capital" in postdisaster recovery (Aldrich, 2012). Perspectives within the existing disaster management literature have moved away from seeing natural disasters as acts of nature towards ideas that human activity and negligence are equally if not more to blame for such 
events and their impacts (O'Brien, O'Keefe, Gadema, \& Swords, 2010). Though spectator security has always been a priority, large-scale threats such as terrorism or natural hazards have become even more critical management concerns. As such, communities, identities, and the social constructions of fans and their fan bases assume greater importance from a sport management perspective, worthy of further investigation.

\section{The Nexus of Sports and Venue Resilience and Cascading Disasters}

As previously highlighted, sport event narratives relating to stakeholder involvement also encompass risk management dimensions, not least because ensuring a safe, secure environment is a priority for all stakeholders involved in delivering sports events (Hall et al., 2012). The growing profile of global sports events has resulted in increased exposure to risks that affect all stakeholders, including spectators and participants (Shipway \& Fyall, 2012). Hence, as identified above, risk management is a defined and acknowledged aspect of sport event management studies. This is not least because security costs are associated with implementing protective measures, including staffing, physical protection systems, perimeter control, access control, risk management, emergency management, crowd management, and traffic control; all form an integral part of international sport event management.

Yet, recent trends such as terrorism have highlighted potential synergies leading to crisis and disaster management being no longer viewed as exceptional expenditure items, or a distinct sphere of activity. According to Alexander (2016), there is a curious paradox about major crises, emergencies, and disasters. On the one hand crises are extraordinary major incidents that require special organization and resources to deal with the disruption they cause, while on the other hand they are sufficiently frequent and similar to each other to be often planned for events. These observations have been recognized by tourism crisis management scholars most notably as part of a growing focus on organizational resilience (Orchiston, Prayag, \& Brown, 2016). Moreover, from the sporting perspective terrorism has been cited as one of the most common risks associated with the security of sporting events (Taylor \& Toohey, 2006, 2007; Toohey \& Taylor, 2008, 2012), with the $9 / 11$ terrorist attacks having a major effect on the financial commitment to safety and security. For example, the London 2012 security costs were estimated at US $\$ 2.2$ billion (Hall et al., 2012). These costs will continue rising given the ongoing global threat of terrorism and crowd management problems inherent with hosting sports mega-events (Shipway \& Fyall, 2012).

In the current global climate, high-profile ISEs, not least as they are deemed flagship events, are desirable terrorist targets for many reasons such as (1) large crowds make it difficult to identify terrorists, (2) presence of high-profile national or international athletes, (3) national or international media audiences, (4) known date, time, and location of events, and (5) proximity of major venues to transportation hubs for quick escape routes (Hall et al., 2012; Tarlow, 2002). This paradox forms an important insight into how resilience should be viewed in relation to sports events and tournaments, as both exceptional events but also reoccurring events that also assume a degree of resonance of business as usual. It also reinforces the fact that a more thorough and systematic focus on ISEs as part of studies of sport event management-based resilience would be highly beneficial (Shipway, 2018).

Furthermore, there is a need to provide greater insight into the cascading effects of disasters for sporting sites. One area of possibility for future investigation is to explore understandings of resilience in relation to how sports events and venues incorporate more sophisticated assumptions of the concept of cascading disasters. Current emergent studies within crisis and disaster management are concerned with this phenomenon where events, in which a primary threat and/or incident, are followed by a sequence of "secondary hazards." Like "toppling dominoes," the implications of the first event (topples the first domino) leads to a sequence of events and impacts (with other dominoes toppling). Each of these subsequent events has its own importance, degrees of damages, and degrees of consequences (Pescaroli \& Alexander, 2015). Therefore, cascading events are events that occur as a direct or indirect result of an initial event. For example, a flash flood or a terrorist attack within a sporting space may disrupt electricity, and as a result of the 
electrical failure this may impact the effective functioning of a sports venue. Subsequently, this might then lead to serious traffic accidents outside the venue that might inhibit evacuation plans or crowd control. Taken together this cascading effect can effectively paralyze a venue as part of the critical infrastructure for the sports event.

Although definitions of cascading effects remain imprecise and debates are moving beyond "domino metaphors" (Pescaroli \& Alexander, 2015), future studies should explore their implications and insights for sport event management studies and resilience perspectives towards ISEs and ISVs. At present, issues of cascading have not received sufficient attention in the sport crisis management literature and have largely remained relatively undiscussed in explicit terms even in key reviews of existing literature within tourism studies (Jiang et al., 2017; Mair et al., 2016). Understanding how disasters cascade should provide more detailed considerations when making contingencies, and may affect future calculations of the human, physical, and financial costs of maintaining sport event and venue resilience.

\section{Synergizing Public and the Private Dimensions of Sport Event and Venue Resilience}

Often emergency planning is viewed as a primarily public sector-orientated activity given that emergencies often require collective responses involving state actors, public agencies, and first responders (Alexander, 2016). At the same time, there are scholars that focus on resilience of the private sector and resilience dynamics and aspects of supply chain management and the effects on small and medium-sized enterprises (Ates \& Bititci, 2011; Burnard \& Bhamra, 2011; Wishart, 2018) that regard business resilience as relatively distinctive. There is also a propensity within existing literature on disaster management that assumes a disaster is based on its ability to overwhelm existing systems and societies (both public and private) involving escalation that requires regional, national, and even international coordination and assistance.

The COVID-19 pandemic represents a highprofile example of the stress and strain placed on the body of systems, assets, and networks, especially in relation to "lock-down" strategies designed to promote containment and reduce communicable transmission of disease (Remuzzi \& Remuzzi, 2020). The same rather fragmented expectations often apply to ISEs given that it is often a city or a nation that is bidding for, or hosting, a specific sports event. In doing so, they are also aiming to achieve wide-scale sports participation, investment, and hopeful evolution of legacies for the host city, region, and country. Yet, it is not always the case that the sports venues and facilities are publicly owned. For example, in the Football Association context of either the FIFA World Cup or European Championship tournament, most of the stadiums used are owned by the respective clubs and/or private management companies. These organizations will often have their own, sometimes divergent, private-orientated resilience, and emergency planning practices. Hence, while global sport tournaments and events will be legally obliged to meet international public norms, legislation, and standards, in practice there is substantial room for variations even between the venues operating within any single sporting tournament.

Similarly, the governing bodies and federations of sport and organizers of high-profile global sports events are not always public-sector organizations. They are often private sector initiatives or governing bodies, like Formula 1 motor racing, or even the International Olympic Committee (IOC). As such, more extensive levels of sport venue resilience should include more sophisticated appreciations that disaster management is often as much a private as a public sector activity, or more accurately the coordination of both. UN Frameworks like Sendai envisage more extensive use of public-private partnerships (PPPs) in disaster management (United Nations, 2014). Scholars of disaster management have increasingly recognized the challenges in effectively facilitating these given there are differing practices used by the public and private spheres of disaster management (Auzzir, Haigh, \& Amaratunga, 2014). In the context of sport event management studies, there are also particular challenges in making PPPs work in developing countries. This challenge is experienced by sports global governing bodies and international federations seeking to extend the reach of global sporting tournaments to the developing world.

Yet, for the most part, the increasing attention to PPPs in enhancing resilience has not been the 
subject of overt explicit discussion in the fields of either sport or event management or crisis management. This remains relatively undiscovered academic territory that merits further scrutiny. Hence, there is considerable future work to be undertaken in the sport event management contexts to explore: (1) any synergies in how sport event management and disaster management have approached the issue of PPPs, and (2) in recognizing that emergency and disaster management of ISEs, be they mega-, large, and/or small scale (Müller, 2015; Shipway $\&$ Miles, 2020), also need to factor in qualitative variations in public and private sector ownership, and the overall effects on planning and procedures when handling natural or man-made incidents.

\section{Crisis Communication: Handling Issues of Reputational Risk, Litigation, and Culpability}

A further future line of enquiry links to understanding how resilience is factored into the management of ISEs and ISVs in terms of communication strategies. Although most fields, including tourism crisis and disaster management scholars, have focused on crisis communications (Schroeder \& Pennington-Gray, 2015), in the sports event context further work is required on understanding the concept of blame management of expectations. This is an area that has been "a bastion" for wider crisis communications scholars (Brändström, 2016). For example, at both the 2010 Commonwealth Games in India and the 2016 Olympic and Paralympic Games in Brazil, blame was placed on organizing committees for not fully delivering on certain expectations (Shipway \& Miles, 2019; Walters et al., 2017). Likewise, blame is frequently placed on policymakers in host countries for not delivering envisaged legacy effects to host regions and/or countries pre-, during, and after the event (Preuss, 2007). As such the performance of tournaments, events, and venues are integrally related to thinking about reputational risk, and the possibilities of future litigation and culpability for ISEs that could potentially underperform and fail to deliver on expectations.

Modern society is experiencing high levels of connectivity and communication technologies have given crises and emergencies an increasing sense of immediacy to people who are not directly involved in global incidents, but who observe them through television images and social media outlets. The global media thirst for frequent updates during the COVID-19 pandemic and the public search for accurate information illustrated this immediacy (Heymann \& Shindo, 2020). Growing public awareness and interest in crises, emergencies, and disasters is resulting in greater efforts to increase resilience (Miles, 2016b). With the advent of social media, the "time windows" for sport event managers to handle, process, and control crisis communication are ever shorter and more complex (Alexander, 2014). This remains highly challenging at notable ISEs, and thus offers opportunities for further investigation. It is likely that, as part of commitments to disaster risk reduction, mitigation, and prevention, more sophisticated resilience messages for ISEs and ISVs will increasingly feature more prominently.

In the field of crisis and disaster management studies there has been considerable work on understanding the nuances of crisis communication, including analyzing variations in relation to differing types of threats and hazards, and evaluating obstacles to effective crisis communication (Miles, Gordon, \& Bang, 2017), social media impacts (Alexander, 2014), and the centrality of blame management (Brändström, 2016; Ewart \& MacLean, 2015). In the sporting arena there is merit in exploring how these sophisticated interpretations of crisis communication could complement sport media management studies and the strategies of ISEs and ISVs, when their resilience is tested by incidents, crises, and disasters. Fundamentally, poor crisis communication during a sport event or tournament, or for a sports venue, will have substantial implications for overall reputational risk. It can lead to review, litigation, and culpability during postrecovery phases that can substantially tarnish and even ultimately threaten the continuity of a sport event or venue, if they are regarded as "unsafe" and/or "insecure" (Shipway \& Miles, 2019).

\section{Simulating Disaster Scenarios for International Sports Events and Venues}

Part of ensuring stronger resilience at ISEs and ISVs revolves around more detailed and sophisticated understandings of both learning and reviewing resilience. If future sport event management 
studies wish to utilize more complex classifications to encapsulate their varying degrees of complexity, scope, scale, reach, and impact (Shipway \& Miles, 2020) of ISEs, then this has implications for corresponding understandings of vulnerability. This must not only be planned for, via emergency plans, policies, and procedures (see Alexander, 2016), but also tested and evaluated. In the field of disaster management studies, there is currently considerable focus on the role and importance of scenario building, simulations, and review, as part of testing, learning, and reviewing (Bosomworth, Owen, \& Curnin, 2017). This constitutes an integral part of both "bouncing back and bouncing forwards" from disasters as part of increased resilience (Shipway \& Miles, 2019; Zebrowski, 2016).

Although this is implicit within notions of resilience being built into classifications and features of ISEs, there is significant future scope for the current body of knowledge from disaster management on simulations and scenario building to act as a foundation for further dialogue with sport event management studies that practically analyze the effective functioning of tournaments, events, and venues. In practical terms, simulations and scenario building represent a critical part of demonstrating sport event and venue resilience. As ISEs continue to "bounce back" from the catastrophic impacts of COVID-19, mechanisms to support more detailed and sophisticated understandings of both learning and reviewing resilience are of increasing importance.

\section{Conclusions}

This article explores ISEs through the lens of resilience and reveals how both sport and event studies could be better informed by disaster management and resilience studies. The global societal impact of the COVID-19 pandemic highlights the timely importance and urgent need for a far greater body of knowledge in this area (Gilbert et al., 2020). It contributes new knowledge by proposing an interdisciplinary research agenda for sport and event management studies, centered around eight key thematic resilience areas. The article also introduces the concept of sport event and venue resilience, which is currently attracting the attention of, and gaining traction with, practitioners in the international disaster management academic and practitioner communities. This highlights potential future international research impact. Policy and practice implications for governments, local authorities, international federations, and governing bodies of sport, sports events, and sports organizations are integrated throughout. The article then concludes by proposing a thematic framework for better understanding crisis and disaster management at ISEs and ISVs.

It must also be acknowledged that one limitation of this article is that these eight identified research agendas have primarily emerged from previous work and extensive studies within the domain of crisis and disaster management and have yet to be empirically tested in sport event-related settings to either verify or refute their applicability. As such, this is the very challenge proposed for both established and emerging scholars of ISEs, and within the broader domain of critical event studies.

The main themes identified in the article intersect with several social science disciplines including sociology, social psychology, communication studies, economics, geography, and political science, to name a few examples. Many of the key themes identified (e.g., an exploration of crowd/ fan behaviors, the risk perceptions of sport fans, or aspects of social, community and individual resilience) address human behavior as it occurs in sport, event, and leisure society. In doing so, the article firmly advocates future studies that help us better understand how groups of people act and interact at sports events. This interdisciplinary approach draws from the past and present experiences of studies from crisis, disaster, and emergency management that are embedded in social science perspectives.

By harnessing this potential for closer synergies between both sport and event management studies and crisis and disaster management fields, there are notable possibilities to substantially move forward our understanding of the complexities of ISEs, both in terms of theory and practice. As identified above, not only is there a pressing interdisciplinary research agenda centering around the eight resilience areas, but there are notable practical implications that should give ISEs a better "sporting chance" of handling crisis and disasters in the future.

In addition, disaster managers would most certainly benefit from better understanding particular sporting nuances, such as the peculiarities around 
fandom. This will help facilitate more effective disaster management. One thing is certain, neither the schedules of future ISEs and ISVs nor the likelihood of future threats and hazards will wait for scholars of sport event management and crisis and disaster management to open up a more effective dialogue. As the COVID-19 pandemic so dramatically illustrated, the implications of future delay could be significant, not just in affecting future sports events and tournaments, but also in costing lives, casualties, and incurring major damage if these contemporary resilience agendas are not promptly investigated and addressed.

\section{References}

Adger, W. N. (2006). Vulnerability. Global Environmental Change, 16(3), 268-281.

Aldrich, D. P. (2012). Building resilience: Social capital in post-disaster recovery. Chicago, IL: University of Chicago Press.

Alexander, D. (2013). Resilience and disaster risk reduction: An etymological journey. Natural Hazards and Earth Systems Sciences Discussions, 1, 1257-1284.

Alexander, D. (2014). Social media in disaster risk reduction and crisis management. Science and Engineering Ethics, 20, 717-733.

Alexander, D. (2016). How to write an emergency plan. London, UK: Dunedin.

Aliperti, G., Sandholz, S., Hagenlocher, M., Rizzi, F., Frey, M., \& Garshagen, M. (2019). Tourism, crisis, disaster: An interdisciplinary approach. Annals of Tourism Research, 79. doi: https://doi.org/10.1016/j.annals.2019.102808

Ammon, R., Southall, R., \& Blair, D. (2004). Sport facility management: Organizing events and mitigating risks. Morgantown, WV: Fitness Information Technology Inc.

Ates, A., \& Bititci, U. (2011) Change process: A key enabler for building resilient SMEs. International Journal of Production Research, 49(18), 5601-5618.

Atkinson, C. L. (2012). Toward resilient communities. London, UK: Routledge.

Auzzir, Z. A., Haigh, R. A., \& Amaratunga, D. (2014). Public-private partnerships (PPP) in disaster management in developing countries: A conceptual framework. Procedia: Economics and Finance, 18, 807-814.

Boin, A., \& McConnell, A. (2007). Preparing for critical infrastructure breakdowns: The limits of crisis management and the need for resilience. Journal of Contingencies and Crisis Management, 15(1), 50-59.

Bosomworth, K., Owen, C., \& Curnin, S. (2017). Assessing challenges for future strategic level emergency management: Reframing, networking, and capacity-building. Disasters, 41(2), 306-323.

Brändström, A. (2016). Crisis, accountability and blame management. Stockholm, Sweden: CRISMART.
Bhamra, R. (Ed.). (2016). Organisational resilience. Boca Raton, FL: CRC Press.

Burnard, K., \& Bhamra, R. (2011). Organisational resilience: Development of a conceptual framework for organisational responses. International Journal of Production Research, 49(18), 5581-5599.

Carey, K. M., \& Mason, D. S. (2016). Damage control: Media framing of sport event crises and the response strategies of organizers. Event Management, 20(2), 119-135.

Coaffee, J., \& Fussey, P. (2017). Politics of security-driven resilience. In D. Chandler \& J. Coaffee (Eds.), The Routledge handbook of international resilience (pp. 293 306). London, UK: Routledge.

Chandler, D., \& Coaffee, J. (2017). Introduction: Contested paradigms of international resilience. In D. Chandler \& J. Coaffee (Eds.), The Routledge handbook of international resilience (pp. 3-90). London, UK: Routledge.

de Milliano, C., \& Jurriens, J. (2017). A different cup of tea. In D. Chandler \& J. Coaffee (Eds.), The Routledge handbook of international resilience (pp. 260-261). London, UK: Routledge.

Dickson, T. J., Benson, A. M., \& Blackman, D. A. (2011). Developing a framework for evaluating Olympic and Paralympic legacies. Journal of Sport and Tourism, 16(4), 285-302.

Doukas, S. G. (2006). Crowd management: Past and contemporary issues. The Sport Journal, 9(2), 2-18.

European Commission. (2015). Secure societies-Protecting freedom and security of Europe and its citizens. Retrieved from https:/ec.europa.eu/programmes/horizon2020/en/ h2020-section/secure-societies-\%E2\%80\%93protecting-freedom-and-security-europe-and-its-citizens

Evans, N., \& Elphick, S. (2005). Models of crisis management: An evaluation of their value for strategic planning in the international travel industry. International Journal of Tourism Research, 7(3), 135-150.

Ewart, J., \& MacLean, H. (2015). Ducking for cover in the 'blame game': News framing of the findings of two reports into the 2010-11 Queensland floods. Disasters, 39(10), 166-184.

Faulkner, B. (2001). Towards a framework for tourism disaster management. Tourism Management, 22, 135-147.

Filimonau, V., \& De Coteau, D. (2020). Tourism resilience in the context of integrated destination and disaster management (DM2). International Journal of Tourism Research, 22, 202-222.

Filo, K., Cuskelly, G., \& Wicker, P. (2015). Resource utilisation and power relations of community sports clubs in the aftermath of natural disasters. Sport Management Review, 18, 555-569.

Galli, N., \& Gonzalez, S. P. (2015). Psychological resilience in sport: A review of the literature and implications for research and practice. International Journal of Sport and Exercise Psychology, 13(3), 243-257.

Getz, D. (2008). Event tourism: Definition, evolution, and research. Tourism Management, 29, 403-428.

Gilbert, M., Pullano, G., Pinotti, F., Valdono, E., Paletto, C., Boelle, P.-V., . . \& Colizza, V. (2020). Preparedness 
and vulnerability of African countries against importations of COVID-19: A modelling study. The Lancet, 395, 871-877.

Haldrup, S. V., \& Rosen, F. (2013). Developing resilience: A retreat from grand planning. Resilience, 1(2), 130-145.

Hall, S. (2016). Crisis management. In T. Byers (Ed.), Contemporary issues in sports management (pp. 391-403). London, UK: SAGE.

Hall, S. A., Cooper, W. E., Marciani, L., \& McGee, J. A. (2012). Security management for sports and special events: An interagency approach to creating safe facilities. Champaign, IL: Human Kinetics.

Hall, S. A., Marciani, L., Cooper, W. E., \& Rolen, R. (2008). Introducing a risk assessment model for sports venues. The Sports Journal, 21. Retrieved from https://the sportjournal.org/article/introducing-a-risk-assessmentmodel-for-sport-venues/

Heath-Kelly, C. (2017). Resilience and disaster sites. In D. Chandler \& J. Coaffee (Eds.), The Routledge handbook of international resilience (pp. 307-317). London, UK: Routledge.

Heymann, D., \& Shindo, N. (2020). COVID-19: What next for public health? The Lancet, 395(10224), 542-545.

Higham, J. (2005). Sport tourism destinations: Issues, opportunities and analysis. Oxford, UK: Elsevier.

Higham, J., \& Hinch, T. (2018). Sport tourism development (3rd ed.). Bristol, UK: Channel View.

Hiller, H. (2000). Toward an urban sociology of mega events. Research in Urban Sociology, 5, 181-205.

Horne, J. (2007). The four "knows" of sports mega events. Leisure Studies, 26, 81-96.

Inoue, Y., Funk, D. C., Wann, D. L., Yoshida, M., \& Nakazawa, M. (2015). Team identification and postdisaster social wellbeing: The mediating role of social support. Group Dynamics: Theory, Research, and Practice, 19(1), 31-44.

Inoue, Y., \& Havard, C. T. (2015). Sport and disaster relief: A content analysis. Disaster Prevention and Management, 24(3), 355-368.

Jago, L., \& Shaw, R. (1998). Special events: A conceptual and differential framework. Festival Management \& Event Tourism, 5(1/2), 21-32.

Jiang, Y., \& Ritchie, B. W. (2017). Disaster collaboration in tourism: Motives, impediments and success factors. Journal of Hospitality and Tourism Management, 31, 70-82.

Jiang, Y., Ritchie, B. W., \& Benckendorff, P. (2017). Bibliometric visualisation: An application in tourism crisis and disaster management research. Current Issues in Tourism, 22(16), 1925-957. doi: https://doi.org/10.1080/136 83500.2017 .1408574

Jones, I. (2008) Sports fans and spectators as sport tourists. Journal of Sport and Tourism, 13(3), 161-164.

Kerslake Arena Review. (2018). The Kerslake report: An independent review into the preparedness for, and emergency response to, the Manchester Arena attack on 22nd May 2017. Manchester, UK: Kerslake Arena Review.

Kozak, M., Crotts, J. C., \& Law, R. (2007). The impact of the perception of risk on international travellers. International Journal of Tourism Research, 9(4), 233-242.
Laws, E., \& Prideaux, B. (Eds.). (2006). Tourism crises: Management responses and theoretical insight. London, UK: Routledge.

Leopkey, B., \& Parent, M. M. (2009). Risk management issues in large-scale sporting events: A stakeholder perspective. European Sport Management Quarterly, 9(2), 187-208.

Lock, D., \& Heere, B. (2017). Identity crisis: A theoretical analysis of "team identification" research. European Sport Management Quarterly, 17(4), 413-435.

Mair, L., Ritchie, B., \& Walters, G. (2016). Towards a research agenda for post-disaster and post-crisis recovery strategies for tourist destinations: A narrative review. Current Issues in Tourism, 19(1), 1-26.

Masteralexis, L. P., Barr, C. A., \& Hums, M. A. (2012). Principles and practice of sport management: fourth edition. London, UK: Jones and Bartlett Learning.

Miles, L. (2016a). The five "C's": Synergies in international disaster management and public health and a place for entrepreneurial resilience? Perspectives in Public Health, 136(6), 323-325.

Miles, L. (2016b). Entrepreneurial resilience. Crisis Management Journal, 11(4), 52-54.

Miles, L., Gordon, R., \& Bang, H. (2017). Blaming active volcanoes or active volcanic blame? Volcanic crisis communication and blame management in the Cameroon. In C. J. Fearnley, D. K. Bird, K. Haynes, W. J. McGuire, \& G. Jolly (Eds.), Observing the volcanic world: Volcanic crisis communication (pp. 1-15). New York, NY: Springer.

Müller, M. (2015). What makes an event a mega-event? Definitions and sizes. Leisure Studies, 34(6), 627-642.

O’Brien, G., O'Keefe, P. O., Gadema, Z., \& Swords, J. (2010). Approaching disaster management through social learning. Disaster Prevention and Management: An International Journal, 19(4), 498-508.

Orchiston, C., Prayag, G., \& Brown, C. (2016). Organisational resilience in the tourism sector. Annals of Tourism Research, 56, 145-148.

Pescaroli, G., \& Alexander, D. (2015). A definition of cascading disasters and cascading effects. Going beyond the “toppling dominoes” metaphor. Planet@risk, 3(1), Special Issue on the 5th IDRC Davos 2014, March 2015.

Preuss, H. (2007). The conceptualisation and measurement of mega sport event legacies. Journal of Sport \& Tourism, 12(3-4), 207-228.

Pyke, J., De Lacy, T., Law, A., \& Jiang, M. (2016). Building small destination resilience to the impact of bushfire: A case study. Journal of Hospitality and Tourism Management, 28, 49-58.

Pyke, J., Law, A., Jiang, M., \& De Lacy, T. (2018). Learning from the locals: The role of stakeholder engagement in building tourism and community resilience. Journal of Ecotourism, 17(3), 206-219.

Qi, C., Gibson, H. J., \& Zhang, J. J. (2009). Perceptions of risk and travel intentions: The case of China and the Beijing Olympic Games. Journal of Sport and Tourism, 14(1), 43-67. 
Reisinger, Y., \& Mavondo, F. (2005). Travel anxiety and intentions to travel internationally: Implications of travel risk perception. Journal of Travel Research, 43(3), 212-225.

Remuzzi, A., \& Remuzzi, G. (2020). COVID-19 and Italy: What next? The Lancet. Retrieved 20 from https:// www.thelancet.com/action/showPdf? pii $=$ S01406736\%2820\%2930627-9

Ritchie, B. W. (2004). Chaos, crises, and disasters: A strategic approach to crisis management in the tourism industry. Tourism Management, 25, 669-683.

Ritchie, B., Chien, M., \& Sharifpour, R. (2017). Segmentation by travel related risks: An integrated approach. Journal of Travel and Tourism Marketing, 34(1), 274-289.

Santana, G. (2004). Crisis management and tourism: Beyond the rhetoric. Journal of Travel \& Tourism Marketing, 15(4), 299-321.

Schroeder, A., \& Pennington-Gray, L. (2016). The role of social media in international tourist's decision making. Journal of Travel Research, 54(5), 584-595.

Shipway, R. (2007). Sustainable legacies for the 2012 Olympic Games. The Journal of the Royal Society for the Promotion of Health, 127(30), 119-124.

Shipway, R. (2018). Building resilience and managing crises and disasters in sport tourism. Journal of Sport \& Tourism, 22(3), 265-270.

Shipway, R., \& Fyall, A. (Eds). (2012). International sports events: Impacts, experiences and identities. London, UK: Routledge.

Shipway, R., \& Miles, L. (2019). Reputation and perceived resilience in developing countries bidding for major sports events. In G. Walters \& J. Mair (Eds.), Reputation and image recovery for the tourism industry (pp. 148164). Oxford, UK: Goodfellow Publishers.

Shipway, R., \& Miles, L. (2020). Bouncing back and jumping forward: Scoping the resilience landscape of international sports events and implications for events and festivals. Event Management, 24(1), 185-196.

Sönmez, S. F., Apostolopoulos, Y., \& Tarlow, P. (1999). Tourism in crisis: Managing the effects of terrorism. Journal of Travel Research, 38(1), 13-18.

Stevens, A., \& Glendinning, M. (2007). Sports security and safety: Evolving strategies for a changing world. London, UK: Sport Business Group.
Stott, C., Hoggett, J., \& Pearson, G. (2012). "Keeping the peace." Social identity, procedural justice and the policing of football crowds. British Journal of Criminology, $52,381-399$.

Stott, C., West, O., \& Radburn, M. (2016). Policing football "risk?" A participant action research case study of a liaison-based approach to "public order." Policing and Society, 1-16.

Tarlow, P. E. (2002). Event risk management and safety. New York, NY: Wiley.

Tarlow, P. E. (2017). Sports travel security. Oxford, UK: Elsevier.

Taylor, T., \& Toohey, K. (2006). Impacts of terrorism-related safety and security measures at a major sport event. Event Management, 9(4), 199-209.

Taylor, T., \& Toohey, K. (2007). Perceptions of terrorism threats at the 2004 Olympic Games: Implications for sport events. Journal of Sport and Tourism, 12(2), 99-114.

Toohey, K., \& Taylor, T. (2008). Mega events, fear, and risk: Terrorism at the Olympic Games. Journal of Sport Management, 22, 451-469.

Toohey, K., \& Taylor, T. (2012). Surveillance and securitization: A forgotten Sydney Olympic legacy. International Review for the Sociology of Sport, 47(3), 324-337.

Tsai, C. H., \& Chen, C. W. (2011). The establishment of a rapid natural disaster risk assessment model for the tourism industry. Tourism Management, 32(1), 158-171.

United Nations. (2014). Sendai framework for disaster risk reduction, 2015-2030. Retrieved from http://www. unisdr.org/files/43291_sendaiframeworkfordrren.pdf

United Nations Office for Disaster Risk Reduction. (2017). Critical infrastructure and disaster resilience: Issue brief by the private sector (ARISE). New York, NY: Author.

Walters, G., Shipway, R., Miles, L., \& Aldrigui, M. (2017). Fandom and risk perceptions of Olympic tourists. Annals of Tourism Research, 66, 210-212.

Wishart, M. (2018) Business resilience in an SME context: A literature review. Warwick, NY: Enterprise Research Centre.

Zebrowski, C. (2016). The value of resilience: Securing life in the twenty-first century. London, UK: Routledge. 
Copyright of Event Management is the property of Cognizant, LLC and its content may not be copied or emailed to multiple sites or posted to a listserv without the copyright holder's express written permission. However, users may print, download, or email articles for individual use. 